\title{
Türkiye' de Döviz Kurunun Enflasyon Etkisi ve Fiyat Yapışkanlıkları: NARDL Yaklaşımı
}

\author{
Yaşar TURNA ${ }^{1}$, Sami EŞMEN ${ }^{2}$, Başak TURNA ${ }^{3}$
}

Özet

Küreselleşme akımının etkisiyle birlikte ülkeler arasındaki sınırların ortadan kalkması uluslararası mal alışverişlerini hızlandırırken uluslararası alışverişler için gerekli döviz ihtiyacını da artırmaktadır. Bu durum döviz kurunda meydana gelen değişmelerin ekonomi üzerindeki etkisini artırmaktadır. Döviz kurlarında meydana gelen dalgalanmalar ithalata dayalı üretim ya da satış yapan endüstrilerde maliyet artışıyla birlikte yurtiçi fiyatları yükselterek bir enflasyonist sürecin yaşanmasına neden olmaktadır. Dolayısıyla bu çalışmada Türkiye'de 2013Q1-2021Q1 dönemi arasındaki enflasyon ile döviz kuru, ihracat ve ithalat arasındaki asimetrik ilișki NARDL yöntemi ile test edilmektedir. Çalışma sonucunda döviz kuru, ithalat ve ihracatın enflasyon üzerinde asimetrik etkisinin olduğu ve Türkiye' de bu sürecin fiyat yapışkanlıklarına neden olduğu gözlemlenmiştir.

Anahtar kelimeler: Enflasyon, Döviz kuru, Fiyat yapışkanlığı, NARDL

Jel Kodu: F13, F31, F41, F47

\section{The Inflation Effect of Exchange Rate and Price Stickiness in Turkey: NARDL Approach}

\section{Abstract}

With the effect of globalization, the disappearance of borders between countries accelerates international goods exchanges and increases the need for foreign exchange required for international exchanges. This situation increases the impact of changes in exchange rates on the economy. Fluctuations in foreign exchange rates cause an inflationary process by raising domestic prices with an increase in costs in industries that produce or sell based on imports. Therefore, in this study, the asymmetric relationship between inflation and exchange rate, export and import between 2013Q1-2021Q1 in Turkey is tested with the NARDL method. As a result of the study, it has been observed that foreign exchange, import and export have an asymmetric effect on inflation and this process causes price stickiness in Turkey.

Keywords: Inflation, Exchange rate, Price stickiness, NARDL

Jel Codes: F13, F31, F41, F47

ATIF ÖNERİsi (APA): Turna Y., Eşmen S., Turna B. (2022). Türkiye' de Döviz Kurunun Enflasyon Etkisi ve Fiyat Yapışkanlıkları: NARDL Yaklaşımı. İzmir İktisat Dergisi. 37(2). 522-535. Doi: 10.24988/ije.932967

1 Öğr. Gör. Yaşar TURNA, Pamukkale Üniversitesi, Çivril Atasay Kamer Meslek Yüksekokulu, Çivril/DENIZLL̇, EMAIL: yturna@pau.edu.tr ORCID: 0000-0002-3972-9099

2 Öğr. Gör. Sami EŞMEN, Pamukkale Üniversitesi, Çivril Atasay Kamer Meslek Yüksekokulu, Çivril / DENİZLİ, EMAIL: sesmen@pau.edu.tr ORCID: 0000-0002-0156-1390

3 Başak TURNA (Tezli Yüksek lisans Öğrencisi), Pamukkale Üniversitesi, İktisadi ve İdari Bilimler Fakültesi, KINIKLI/ DENIZLİ, EMAIL: basak ay@hotmail.com ORCID: 0000-0002-0414-420X 


\section{GíRiş}

Küreselleşme akımının etkisiyle birlikte ülke ekonomilerinin birbirine entegre olması, ülkeler arasındaki sınırları ortadan kaldırmıştır. Ülkeler arasındaki sınırların ortadan kalkması uluslararası mal alışverişlerini hızlandırırken, uluslararası ticarette kullanılan yabancı para ihtiyacını da artırmıştır. Yabancı paraya duyulan ihtiyaç ise, döviz piyasalarının gelişmesine neden olmuştur. Gelişmekte olan ülkelerin üretim yapılarının daha çok ithal mallara bağlı olması ve sürekli dış ticaret açıkları ile karşı karşıya kalmaları nedeniyle, döviz piyasasında meydana gelen dalgalanmalar az gelişmiş ülkelerin maliyet yapılarını, dolayısıyla da fiyatlarını etkilemektedir (Uçan ve Aytekin, 2017).

Döviz kurunda meydana gelen artışlar ulusal paranın değer kaybetmesine neden olarak (enserten), yurtiçi ithal malların fiyatlarını artırmakta ve enflasyona neden olmaktadır. Döviz kurunun yurtiçi fiyatları bu şekilde etkilemesi geçiş etkisi olarak adlandırılmaktadır. Buna göre döviz kurlarında meydana gelen dalgalanmalar, ithalata dayalı üretim ya da satış yapan endüstrilerde maliyet artışıyla birlikte, yurtiçi fiyatları yükselterek bir enflasyonist sürecin yaşanmasına neden olmaktadır (Ekinci ve diğerleri, 2015:84). Geçiş etkisi daha geniş çerçevede incelendiğinde içerisinde çeşitli dinamikleri barındırmaktadır. Bu dinamikler, uluslararası ticarette kullanılan mallar ile dış ticarete yönelik üretim yapan sektörlerin yapısı, üretimde kullanılan girdi bileșenleri, döviz kuru dalgalanmalarının büyüklügü ve yönü olarak sıralanabilir. Uluslararası ticarete konu olan mallar ve bu sektörlerin yapısı ile ilgili olarak, ihracatçı firmaların fiyatlama davranışları, ithalatçı ülkede yurtiçi fiyatların yükselmesine ve enflasyona neden olmaktadır (Akın ve Monfared, 2017: 330-331). Bu durumda tam bir geçiş etkisi söz konusu olmaktadır. Bunun aksine malların ithalatçı ülke para birimiyle değerlendiği, yani döviz kurundaki değişmelerin fiyatları etkilemediği durumda ise geçiş etkisi sıfır olmaktadır. Bu durumda ise döviz kurunda meydana gelen dalgalanmalar ihracatçlların kâr marjında değişkenliğe neden olmaktadır. Ayrıca ithalatçı ülkede rekabetçi yapının olmadığı durumlarda ise, ihracatçlların kar marjları kurdaki dalgalanmalara daha az tepki vermektedir. Geçiş etkisinin bir başka unsuru ise döviz kurundaki dalgalanmaların büyüklüğü ile ilgilidir. Döviz kurundaki dalgalanmalar küçük olduğunda, fiyatların değişim maliyetleri göz önünde bulundurularak, dalgalanmalardan kaynaklanan fiyat hareketleri yurtiçi fiyatlara yansıtılmamaktadır. Geçiş etkisini etkileyen bir başka unsur ise ülkede geçerli olan döviz kuru rejimi olarak dikkat çekmektedir. Enflasyon hedeflemesi rejiminin uygulandığı ekonomilerde, dalgalı kur politikasının uygulanması döviz kuru ile yurtiçi fiyatlar arasındaki ilişkiyi zayıflatmaktadır (Damar, 2010:1-6).

Türkiye 1970' li yıllardan itibaren kronik enflasyon problemi yaşamaya başlamış, yaşanan enflasyonist süreç ekonomi üzerinde olumsuzluklara ve istikrarsızlıklara neden olmuştur. 1980'li yıllarda ise, Türkiye ekonomisinde yaşanan dönüşüm neticesinde açlklanan istikrar programıyla yüksek enflasyon ve döviz darboğazının çözülmesi amaçlanmıştır. Bu istikrar programı ile birlikte dış ödemeler dengesi açıklarının giderilmesi, reel döviz kuru aracılığıyla ihracatın artırılması, enflasyonun dış rekabette yarattığı olumsuz etkilerin giderilmesi ve beklentilere cevap verilebilmesi amacıyla, döviz kurunda günlük ayarlamalara gidilmiştir. Bunun sonucu olarak, 1981 yılında kurların günlük ilan edilmesi vasıtasıyla esnek kur sistemine geçilmiş ve bu sistem küçük revizyonlarla 1999 yılına kadar uygulanmıștır. Öte yandan Türkiye, IMF ile 1998 yılında yapmış olduğu anlaşma gereği uygulamış olduğu döviz kuru politikasını değiştirme kararı almıştır. Buna göre, Türkiye 18 aylık süreci esas alan döviz kuruna dayalı kur sepetini uygulamaya başlamıştır. Bu anlaşma Türkiye' de döviz kurunun beklenen düzeye çekilmesi, orta ve uzun vadede beklentilere karşılık verilerek döviz kurundaki belirsizliklerin ortadan kaldırılması ve bu sayede fiyat istikrarının da sağlanması amacıyla uygulamaya konulmuştur (Gül ve Ekinci, 2015:165-166). Ancak bu program Şubat 2001 krizi ile birlikte geçerliliğini yitirerek döviz kuru piyasa dalgalanmalarına bırakılmıştır. Krizin etkileri devam ederken, 2001 yılı mayıs ayında uygulamaya konulan güçlü ekonomiye geçiş programı ile birlikte 
enflasyon oranları düşme eğilimine girse de, istenilen düzeyde gerçekleşmemiştir. Sonrasında 2006 yılında uygulanan enflasyon hedeflemesi rejimi ise, yıl sonunda beklenen sonuca ulaşamamış ve başarısız olmuştur. Devam eden süreçte ise, 2008 yılında meydana gelen küresel finansal kriz ile birlikte, Türkiye' de enflasyon oranı artmıș, döviz kurunda meydana gelen dalgalanmalar ekonomide durgunluk sürecinin yaşanmasına neden olmuştur.

Yapılan bu açıklamalara istinaden Türkiye' de ithal bağımlılığının yüksek olması neticesinde döviz kurunda meydana gelen dalgalanmaların enflasyonist etki yarattığı düşünülmektedir. Aynı zamanda kurdaki artışın ihracatı artırıcı etkisi ile birlikte, yurtiçi döviz miktarında artışın kurdaki dalgalanmaları azaltarak enflasyonu baskılaması beklenmektedir. Ancak döviz kurunda meydana gelen dalgalanmalar sonucunda, ithalatın enflasyonist etkisi ile ihracatın enflasyonu baskılayan etkisi aynı miktarda gerçekleşmemektedir. Bu durum neticesinde ise kurdaki dalgalanmalar ithalat ve ihracat miktarlarındaki değişmeler göz önüne alındığında, sürekli fiyat artışlarını tetiklemektedir. Bu enflasyonist süreç aslında fiyat yapışkanlıklarını da beraberinde getirmektedir. $\mathrm{Bu}$ nedenle bu çalışmada Türkiye'de 2013Q1-2021Q1 dönemi arasındaki enflasyon ile döviz kuru, ihracat ve ithalat arasındaki asimetrik ilişki test edilmektedir. Bu asimetrik ilişki döviz kuru dalgalanmalarının ithalat ve ihracat miktarlarında meydana getirdiği değişimler neticesinde yurtiçi fiyat düzeyi üzerindeki döviz kuru etkisini ve dolayısıyla fiyat yapışkanlıklarını göstermesi bakımından önem arz etmektedir

\section{LİTERATÜR TARAMASI}

Literatürde döviz kuru ile enflasyon arasındaki ilişkiyi inceleyen yerli ve yabancı birçok çalışma olmasına rağmen çalışmalarda farklı sonuçların ortaya çıkması dikkat çekmektedir. Bunun nedeni olarak yapılan analizlerde kullanılan veri seti, örneklem ya da yöntemlerin farklı olması gösterilebilir. Dolayısıyla literatürde farklı sonuçları içeren bazı çalışmalar değerlendirildiğinde, Döviz kuru ile enflasyon arasındaki ilişki konusunda 1984 yılında Woo'nun açıklamaları dikkat çekmektedir. Buna göre ithal edilen malların fiyatları tüketici fiyat endeksini doğrudan etkilemektedir. Ayrıca ithal mallarının fiyatlarında meydana gelecek değișmelerde yerli malların fiyatlarını doğrudan etkilemektedir. Dolayısıyla döviz kurundaki dalgalanmalar toplam talebi etkileyerek fiyatların artmasına neden olmaktadır. Bu konuda bir başka çalışma 1987 yılında Rudiger Dornbusch tarafından yapılmıştır. Dornbusch döviz kuru ile fiyatlar arasındaki ilişsiyi inleyerek enflasyonun döviz kurundan etkilendiğini vurgulamıștır. Svensson' a (2000) göre kur atıșılla birlikte ithal malların fiyatlarındaki artış, net ihracatı etkileyerek, enflasyona neden olmaktadır. Ayrıca TÜFE sepetinde ithal malların miktarının fazla olması döviz kurundaki artışların enflasyon üzerindeki etkisinin de daha büyük olacağını göstermektedir. Durevall ve Ndung'u (2001) Kenya' da enflasyonun nedenlerini analiz ettikleri çalışmalarında döviz kurunun enflasyon üzerindeki etkisinin uzun dönemde çok daha fazla hissedildiği bulgusuna ulaşmışlarıdır. Ayrıca döviz kurunun etkisiyle artan fiyatların dengeye geri dönme hızı ise yavaş olarak gözlemlenmiştir. Kara ve Nelson (2002) İngiltere' de döviz kuru ile enflasyon arasındaki ilişkiyi inceledikleri çalışmada İngiltere ekonomisinde döviz kurunun enflasyonist etkisinin çok düşük seviyede olduğu sonucuna ulaşmışlardır. Bayraktutan ve Aslan (2003) yaptıkları çalışmada Türkiye' de döviz kuru, ithalat ve enflasyon arasındaki nedensellik ilişkisini test etmişlerdir. Buna göre döviz kuru enflasyonu ithalat hacmindeki değişmeler aracılığıyla dolaylı olarak etkilemektedir. Crucini ve diğerleri (2013) yaptıkları çalışmada AB ülkeleri için zamana bağlı bir Calvo fiyatlandırma modeli kullanarak reel döviz kuru ile fiyat yapışkanlığı arasındaki ilişkiyi gösteren reel döviz kuru dalgalanma eğrisi geliştirmişlerdir. Buna göre AB ülkelerinde dalgalanma eğrisi U şeklinde olmakla birlikte, bu eğriyi minimum yapan fiyat yapışkanlığının bire yakın seviyede olduğu tespit edilmiştir. Sheefeni ve Ocran (2014) Namibya' da döviz kuru ile enflasyon arasındaki ilişkiyi SVAR yöntemi ile test etmişlerdir. Çalışma sonucunda uzun dönemde döviz kurunun enflasyon üzerinde önemli bir etkisi vardır. Özcan (2014) gelişmekte olan 44 ülkede döviz kuru ile enflasyon arasındaki ilişsiyi dinamik panel veri 
analizi yöntemiyle test etmiştir. Çalışmanın sonucunda döviz kurunda meydana gelen artışların yerli paranın değer kaybetmesiyle birlikte enflasyona neden olduğu sonucuna ulașılmıștır. Ebiringa ve Anyaogu (2014) ise döviz kuru ile enflasyon arasındaki eş bütünleşme ilişkisini ARDL yöntemi ile test etmiş ve döviz kuru ile enflasyon arasında uzun dönemli ilişkinin olduğu sonucuna ulaşmışlardır. Altıntaş (2014) Türkiye'de döviz kuru ile enflasyon arasındaki ilişkiyi test ettiği çalışmasında uzun dönemde döviz kurundaki dalgalanmaların enflasyona neden olduğu sonucuna ulaşmıştır. Nchor ve Darkwah (2015) çalışmalarında Gana ekonomisinde uzun dönemde enflasyon ile döviz kuru arasında pozitif yönlü bir ilişki tespit etmişlerdir. Moroşan ve Zubaş (2015) Romanya ekonomisi için yaptıkları çalışmalarında döviz kurunda meydan gelen değişmelerin enflasyonu aynı dönemde etkilemediği farklı dönemlerde etkilediği sonucuna ulaşmışlardır. Agénor ve Montiel (2015)' e göre döviz kurunda meydana gelen değişmeler dışa açık ve gelişmekte olan bir ekonomide ticarete konu olan malların fiyatlarını doğrudan etkileyebilmektedir. Kurda meydana gelen dalgalanmalar ithal girdilerin yerli para cinsinden değerini artırarak enflasyona neden olabilmektedir. Bu durumda ithal girdilerin fiyatlarındaki artış yurtiçi üreticileri belirsizlik ortamına sürükleyerek fiyatların artmasına neden olabilmektedir. Fetai ve diğerleri (2016) batı balkan ülkelerinde döviz kuru ile enflasyon arasındaki ilişkiyi panel veri analiz yöntemiyle test etmişlerdir. Çalışmanın sonucunda batı balkan ülkelerinde döviz kurundaki değişmelerin enflasyon üzerinde güçlü bir etkisinin olduğu gözlemlenmiştir. Osabuohien ve diğerleri (2018) yaptıkları çalışmada döviz kurunda meydana değişmelerin enflasyon üzerindeki etkilerini GARCH ve VECM yöntemleriyle analiz etmişlerdir. Çalışma sonucunda döviz kuru ile enflasyon arasında kısa dönemde negatif ve zayıf bir ilişki varken, uzun dönemde pozitif ve güçlü bir ilişki tespit edilmiştir. Öner (2018) Türkiye'de döviz kuru ile enflasyon arasındaki nedensellik iliş̧isini test ettiği çalışmasında enflasyon oranının döviz kurundaki değişmelerden etkilenmediği sonucuna ulaşmıştır. Carvalho ve diğerleri (2019) yaptıkları çalışmada döviz kurunun katı fiyat modellerindeki etkisini analiz etmişlerdir. Buna göre döviz kurunun fiyatlar üzerindeki etkisinin sektörlere göre farklılaştığı sonucuna ulaşılmıştır. Duman (2019) Türkiye'de döviz kuru ile enflasyon arasındaki ilişkiyi VAR analizi yöntemiyle test etmiş ve döviz kuru artışlarının enflasyona neden olduğu sonucuna ulaşmışlardır.

\section{VERI SETI VE MODEL}

Çalışmada Türkiye ekonomisinde 2013Q1-2021Q1 dönemi arasında enflasyon ve döviz kuru arasındaki geçiş etkisi NARDL yöntemi ile test edilmektedir. Analizde kullanılan veriler TCMB EVDS veri tabanından elde edilmiş ve aşağıdaki tabloda yer almaktadır.

Tablo 1: Veri seti

\begin{tabular}{ccc}
\hline Değişkenler & Tanımlamalar & Kaynak \\
\hline İNF & Tüketici Fiyat Endeksi (Genel)-Düzey & TCMB \\
DK & (USD) ABD Doları -Düzey & TCMB \\
LnEXP & TOPLAM (Bin ABD Doları)-Düzey & TCMB \\
LnIMP & TOPLAM (Bin ABD Doları)-Düzey & TCMB \\
\hline
\end{tabular}

Çalışmada kullanılan değişkenler basitleştirici olması bakımından INF: Enflasyonu, DK: Döviz kurunu, EXP: İhracatı ve İMP: ithalatı ifade etmektedir. Çalışmada kullanılan değişkenlerden oluşan doğrusal regresyon modeli;

$$
\mathrm{INF}=\beta_{1}+\beta_{2} \mathrm{DK}+\beta_{3} \ln \mathrm{EXP}+\beta_{4} \operatorname{lnIMP}+\varepsilon_{t}
$$

Şeklinde gösterilmektedir. Analizde kullanılan değişkenlerin durağanlık testi ve NARDL sınır testi sonuçları aşağıda tablolar halinde yer almaktadır. 


\section{EKONOMETRIKK METODOLOJI}

Non-linear Autoregressive Distributed Lag (NARDL) yaklaşımı 2014 yılında Shin vd. tarafindan bağımsız değișkenlerin bağımlı değișken üzerindeki asimetrik etkilerini test etmek amacıyla öne sürülmüştür. NARDL yaklaşımı diğer eş bütünleşme testlerine göre farklı durağanlık seviyelerine sahip değişkenlere de uygulanabilmesi açısından avantaj sağlamaktadır. Buna göre değişkenlerin düzeyde [I(0)] ya da farkta [I(1)] durağan olması NARDL testinin uygulanmasına engel değildir. Ancak bu yönteme göre değişkenlerin ikinci farkında [I(2)] durağan olmaması gerekmektedir. Aksi takdirde NARDL yöntemi uygulanamaz. Bu yöntemin diğer eş bütünleşme testlerine göre bir başka avantajı ise küçük örneklemlerde de etkili sonuçlar vermesidir. NARDL yöntemi Pesaran ve Shin (2001) tarafından öne sürülen Auto-Regressive Distrubuted Lag (ARDL) modelinin geliştirilmiş formu niteliğindedir. ARDL metodunda uzun ve kısa dönemde değişkenler arasında bir eş bütünleşme ilişkisine rastlanmasa da aslında içerisinde gizli bir eş bütünleşme ilişkisi barındırabilir. Granger ve Yoon (2002) tarafından öne sürülen gizli eş bütünleşme ilişkisi NARDL metodundan hareketle değişkenlerin pozitif ve negatif kısmi ayrıştırmaları toplamı yapılarak test edilebilir. Dolayısıyla bu ayrıştırmalarla bağımlı ve bağımsız değişkenler arasındaki uzun ve kısa dönemli asimetrik ilişkiler analiz edilebilmektedir (Ceylan ve diğerleri, 2016: 2346-2347). NARDL yönteminde değişkenler arasındaki uzun ve kısa dönemli ilişkiler test edilirken hata düzeltme modelinden (ECM) faydalanılmaktadır. Modelde hata düzeltme modelinin çalışması, ekonomide kısa dönemde meydana gelen şokların ne kadarının uzun dönemde giderildiğini göstermektedir. Bu nedenle genel formda tanımlanan doğrusal hata düzeltme modeli 2'nolu eșitlikte yer almaktadır.

$\Delta \dot{\mathrm{I}} N F_{t}=\alpha+\sum_{i=1}^{n} \beta_{i t} \Delta D K_{i, t-i}+\sum_{i=1}^{n} \Phi_{i t} \Delta \ln E X P_{i, t-i}+\sum_{i=1}^{n} \gamma_{i t} \Delta \ln \mathrm{I} M P_{i, t-i}+\delta_{1 i} D K+\delta_{2 i} \ln E X P_{t-i}+$ $\delta_{3 i} \ln \dot{\mathrm{I}} M P_{t-i}+\varepsilon_{i t}$

$\Delta \dot{\mathrm{I}} N F_{t}=\alpha_{0}+\sum_{i=1}^{p} b_{i} \Delta \dot{\mathrm{I}} N F_{t-i}+\sum_{i=0}^{P} b_{i} \Delta D K_{t-i}+\sum_{i=0}^{q} c_{i} \Delta \ln E X P_{t-i}+\sum_{i=0}^{q} c_{i} \Delta \ln \dot{\mathrm{I}} M P_{t-i}+$ $+\Phi_{1} \ln \dot{\mathrm{I}} N F_{t-1}+\Phi_{2} D K_{t-1}+\Phi_{3} \ln E X P_{t-1}+\Phi_{4} \ln \dot{\mathrm{I}} M P_{t-1}+E C T_{t-1}+\varepsilon_{t}$

1'nolu eşitlik enflasyon ile döviz kuru, ihracat ve ithalat arasındaki simetrik ilişkiyi ifade etmekte, 2'nolu eşitlik ise doğrusal hata düzeltme modelini ifade etmektedir. Kurulan modelde hata düzeltme modelinin çalışması kısa dönemde meydana gelen şokların etkisinin uzun dönemde giderildiğini göstermektedir (Utkulu ve Ekinci, 2016:13). Değişkenler arasındaki gizli eş bütünleşme ilişkisi ise değişkenlerin pozitif ve negatif kısmi ayrıștırma toplamları kullanılarak yapılmaktadır. Bu noktadan hareketle Shin vd. (2014) tarafından değişkenler arasındaki kısa ve uzun dönemli asimetrik ilişkinin bu ayrıştırma yöntemi kullanılarak test edilebileceği öne sürülmüştür. Buna göre değişkenler arasındaki pozitif ve negatif kısmi ayrıştırma toplamları;

$D K^{+}=\sum_{j=1}^{t} \Delta D K_{j}^{+}=\sum_{j=1}^{t} \max \left(\Delta D K_{j}, 0\right) D K^{-}=\sum_{j=1}^{t} \Delta D K_{j}^{-}=\sum_{j=1}^{t} \min \left(\Delta D K_{j}, 0\right)$

$E X P^{+}=\sum_{j=1}^{t} \Delta E X P_{j}^{+}=\sum_{j=1}^{t} \max \left(\Delta E X P_{j}, 0\right)$ ve $E X P^{-}=\sum_{j=1}^{t} \Delta E X P_{j}^{-}=\sum_{j=1}^{t} \min \left(\Delta E X P_{j}, 0\right)$

$\dot{\mathrm{I}} M P^{+}=\sum_{j=1}^{t} \Delta \dot{\mathrm{I}} M P_{j}^{+}=\sum_{j=1}^{t} \max \left(\Delta \dot{\mathrm{I}} M P_{j}, 0\right) v e \dot{\mathrm{I}} M P^{-}=\sum_{j=1}^{t} \Delta \dot{\mathrm{I}} M P_{j}^{-}=\sum_{j=1}^{t} \min \left(\Delta \dot{\mathrm{I}} M P_{j}, 0\right)$

Şeklinde ifade edilmektedir. Bu noktadan hareketle 2'nolu eşitlikte yer alan hata düzeltme modeli NARDL yöntemine uygun olarak düzenlendiğinde;

$$
\begin{aligned}
& \Delta \dot{\mathrm{I}} N F_{t}=\mu+\rho_{y} \dot{\mathrm{I}} N F_{t-1}+\theta^{+} D K_{t-1}^{+}+\theta^{-} D K_{t-1}^{-}+\theta^{+} \ln E X P_{t-1}^{+}+\theta^{-} \ln E X P_{t-1}^{-}+\theta^{+} \ln \dot{\mathrm{I}} M P_{t-1}^{+}+ \\
& \theta^{-} \ln \dot{\mathrm{I}} M P_{t-1}^{-}+\sum_{i=1}^{p-1} \rho_{y} \Delta \dot{\mathrm{I}} N F_{t-i}+\sum_{i=0}^{p-1}\left(w_{i}^{+} \Delta D K_{t-1}^{+}+w_{i}^{-} \Delta D K_{t-1}^{-}\right)+\sum_{i=0}^{p-1}\left(w_{i}^{+} \Delta \ln E X P_{t-1}^{+}+\right. \\
& \left.w_{i}^{-} \Delta \ln E X P_{t-1}^{-}\right)+\sum_{i=0}^{p-1}\left(w_{i}^{+} \Delta \ln \dot{\mathrm{I}} M P_{t-1}^{+}+w_{i}^{-} \Delta \ln \dot{\mathrm{I}} M P_{t-1}^{-}\right)+\varepsilon_{t}
\end{aligned}
$$


Şeklinde gösterilmektedir. Bu eșitlikte değişkenler üzerinde + ve - işaretler pozitif ve negatif kısmi ayrıştırmaları ifade etmektedir. Buna göre asimetrik ilişkinin test edilmesi için kurulan hipotez testi;

$H_{0}: \theta^{+}=\theta^{-} \rightarrow$ Değişkenler arasında simetrik ilişki vardır.

$H_{1}: \theta^{+} \neq \theta^{-} \rightarrow$ Değişkenler arasında asimetrik ilişki vardır.

Şeklinde ifade edilmektedir. $H_{0}$ Hipotezinin reddedilmesi durumunda değişkenler arasındaki uzun dönemli asimetrik ilişkinin varlığı kabul edilmektedir. Uzun dönem pozitif ve negatif katsayılar ise $L_{y^{+}}=\frac{-\theta^{+}}{\rho_{y}}$ ve $L_{y^{-}}=\frac{-\theta^{-}}{\rho_{y}}$ şeklinde hesaplanmaktadır (Utkulu ve Ekinci, 2016:14). Bu eşitlik ve tanımlamalardan hareketle değişkenler arasında asimetrik ilişkinin varlığının test edilmesi durumunda uzun ve kısa dönem asimetrik katsayılarda yorumlanabilmektedir. Bu katsayıların yorumlanmasında "Asimetrik Dinamik Hızlandıran” yaklaşımı kullanılmaktadır. Bu yaklaşıma göre katsayılar;

$m_{h}^{+}=\sum_{j=0}^{h} \frac{\partial \dot{\mathrm{I}} N F_{t+j}}{\partial D K_{t}^{+}}$ve $m_{h}^{-}=\sum_{j=0}^{h} \frac{\partial \dot{\mathrm{I}} N F_{t+j}}{\partial D K_{t}^{-}}$

$m_{h}^{+}=\sum_{j=0}^{h} \frac{\partial \dot{\mathrm{I}} N F_{t+j}}{\partial E X P_{t}^{+}}$ve $m_{h}^{-}=\sum_{j=0}^{h} \frac{\partial \dot{\mathrm{I}} N F_{t+j}}{\partial E X P_{t}^{-}}$

$m_{h}^{+}=\sum_{j=0}^{h} \frac{\partial \dot{\mathrm{I}} N F_{t+j}}{\partial \dot{\mathrm{I}} M P_{t}^{+}}$ve $m_{h}^{-}=\sum_{j=0}^{h} \frac{\partial \mathrm{I} N F_{t+j}}{\partial \dot{\mathrm{I}} M P_{t}^{-}}$

Şeklinde hesaplanarak yorumlanmaktadır.

\subsection{Analiz Sonuçları}

NARDL modelinin uygulanabilmesi için çalışmada yer alan değişkenlerin durağanlık testlerinin yapılması gerekmektedir. Bu nedenle değişkenlerin durağanlık düzeylerinin belirlenmesi amacıyla ADF ve PP birim kök testleri yapılmıştır. Birim kök testi sonuçları tablo 2' de yer almaktadır.

Tablo 2: ADF ve PP birim kök testi sonuçları

\begin{tabular}{|c|c|c|c|c|}
\hline \multirow[t]{2}{*}{ Değişkenler } & \multicolumn{2}{|c|}{ ADF } & \multicolumn{2}{|c|}{ PP } \\
\hline & $I(0)$ & I(1) & I(0) & I(1) \\
\hline$\Delta \mathrm{IINF}$ & 2.64538 & $-3.9310^{* * *}$ & 2.6626 & $-3.901^{* * *}$ \\
\hline$\Delta \mathrm{DK}$ & 0.5934 & $-5.0271^{* * *}$ & 1.5371 & $-4.934^{* * *}$ \\
\hline$\Delta \operatorname{lnEXP}$ & 0.3450 & $-6.0841 * * *$ & $-2.92^{* *}$ & $-11.95^{* * *}$ \\
\hline$\Delta \operatorname{lnİMP}$ & $-2.7446^{*}$ & $-7.3720^{* * *}$ & $-2.676^{*}$ & $-7.450^{* * *}$ \\
\hline
\end{tabular}

***,**,* işaretleri sırasıyla \%1, \%5 ve \%10 düzeyinde anlamlılığı temsil etmektedir.

Tablo 2'de yer alan ADF ve PP birim kök testi sonuçlarına göre değişkenlerden bazılarının düzeyde [I(0)] bazılarının ise farkta [I(1)] durağan olduğu gözlemlenmektedir. Değişkenlerin farklı durağanlık seviyelerinde olmaları ve ikinci farkta [I(2)] durağanlık söz konusu olmadığı için NARDL modelinin uygulanması uygundur. Buna göre NARDL testi sonuçları aşağıdaki tabloda yer almaktadır. 
Tablo 3: NARDL testi sonuçları

\begin{tabular}{cll}
\hline Test & F istatistiği & \multicolumn{1}{c}{ Kritik değer } \\
\hline NARDL Testi & $48.23329^{* * *}$ & \multicolumn{1}{c}{$2.27-3.28(\% 5)$} \\
\hline Kısa ve Uzun Dönem Asimetri & \multicolumn{2}{c}{ Wald Testi } \\
\hline DK & $17.65770^{* * *}$ \\
LnEXP & $7.555133^{* * *}$ \\
LnİMP & $3.295097^{* *}$ \\
\hline
\end{tabular}

***,***, işaretleri sirasıyla $\% 1, \% 5$ ve $\% 10$ düzeyinde anlamlılı̆ı̆ temsil etmektedir.

Tablo 3' te yer alan NARDL testi sonuçlarına göre değişkenler arasında asimetrik bir ilişkinin varlığından söz edilmektedir. Tabloda yer alan F istatistiği sonucu kurulan modelin kritik değerler tablosuna göre \%5 düzeyinde anlamlı olduğunu göstermektedir. Ayrıca yapılan Wald testi sonuçlarına göre değişkenler arasında asimetri ilişkisinin olduğu sonucuna ulaşılmıștır. Buna göre kısa dönem asimetri sonuçları tablo 4' te yer almaktadır.

Tablo 4: NARDL kısa dönem test sonuçları

\begin{tabular}{cccc}
\hline Değişkenler & Katsayılar & Standart Hata & T istatistiği \\
\hline$D K^{+}$ & 0.13212 & 2.359549 & $5.599390^{* * *}$ \\
$D K^{-}$ & -0.27245 & 15.00682 & $-1.815517^{*}$ \\
$\ln E X P^{+}$ & 0.40379 & 15.29304 & $2.640357^{* *}$ \\
$\ln E X P^{-}$ & -0.31842 & 9.454190 & $3.368070^{* * *}$ \\
$\ln \dot{I} M P^{+}$ & 0.29732 & 16.01976 & $-1.856012^{*}$ \\
$\ln \dot{I} M P^{-}$ & -0.19307 & 9.258967 & $-2.085248^{* *}$ \\
\hline
\end{tabular}

***,**,* işaretleri sırasıyla $\% 1, \% 5$ ve $\% 10$ düzeyinde anlamlılı̆̆ı temsil etmektedir.

Tablo 4'te yer alan NARDL kısa dönem test sonuçlarına göre döviz kurunda meydana gelen 1 birimlik artış enflasyonda 0.13 birimlik artışa neden olmakta, 1 birimlik azalma ise enflasyonu 0.27 birim azaltmaktadır. İhracatta meydana gelen \%1'lik artış enflasyonu 0.40 birim artırmakta, \%1'lik bir azalma ise 0.31 birimlik azalmaya neden olmaktadır. İthalatta meydana gelen \%1'lik artış ise enflasyonu 0.29 birim artırmakta, \%1'lik azalma ise enflasyonda 0.19 birimlik azalmaya neden olmaktadır. NARDL uzun dönem test sonuçları değerlendirildiğinde 
Tablo 5: NARDL Uzun Dönem Test Sonuçları

\begin{tabular}{cccc}
\hline Değişkenler & Katsayılar & Standart Hata & T istatistiği \\
\hline$D K^{+}$ & 0.28261 & 4.362201 & $6.478620^{* * *}$ \\
$D K^{-}$ & -0.58278 & 21.98555 & $-2.650759^{* *}$ \\
$\ln E X P^{+}$ & 0.86372 & 33.80563 & $2.554970^{* *}$ \\
$\ln E X P^{-}$ & -0.68112 & 21.38019 & $3.185754^{* * *}$ \\
$\ln \dot{I} M P^{+}$ & -0.12185 & 29.64328 & -0.411087 \\
$\ln \dot{I} M P^{-}$ & -0.41298 & 16.43092 & $-2.513489^{* *}$ \\
\hline
\end{tabular}

***,**,* işaretleri sırasıyla $\% 1, \% 5$ ve $\% 10$ düzeyinde anlamlılı̆̆ı temsil etmektedir.

Tablo 5'te yer alan NARDL uzun dönem test sonuçlarına göre döviz kurunda meydana gelen 1 birimlik artış enflasyonda 0.28 birimlik artışa neden olmakta, 1 birimlik azalma ise enflasyonu 0.58 birim azaltmaktadır. İhracatta meydana gelen \%1'lik artış enflasyonu 0.86 birim artırmakta, \%1'lik bir azalma ise 0.68 birimlik azalmaya neden olmaktadır. İthalatta meydana gelen \%1'lik artışın etkisi anlamlı sonuç vermemekle birlikte \%1'lik azalma enflasyonda 0.41 birimlik azalmaya neden olmaktadır. Ayrıca modelin ne kadar istikrarlı olduğunu ifade eden Cusum ve Cusumq grafikleri Şekil 1' de yer almaktadır.

Şekil 1: Cusum Grafiği
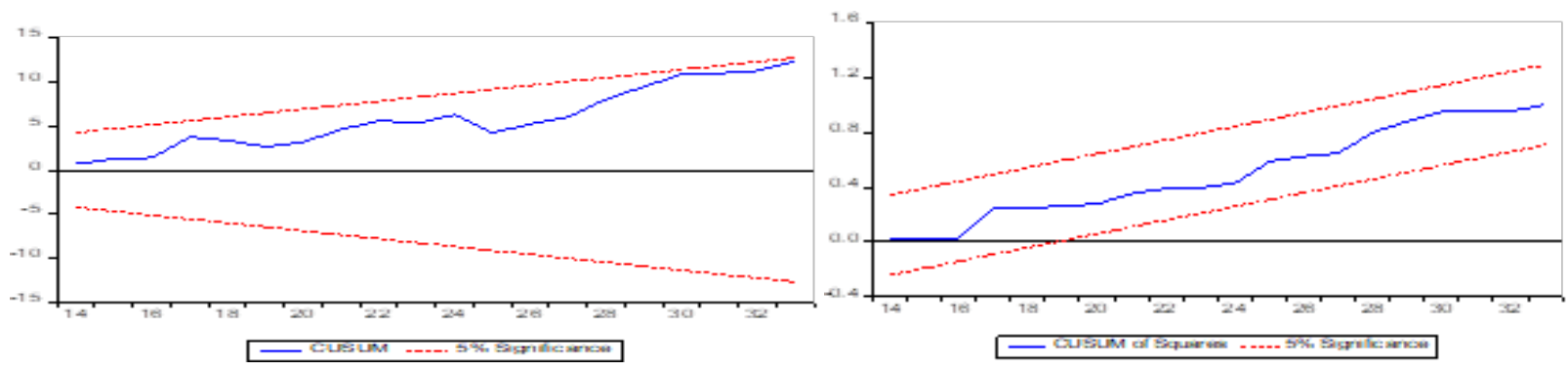

Şekil 1' de yer alan Cusum ve Cusumq grafiklerine göre modelin istikrarlı olduğu, analize konu olan dönemde herhangi bir yapısal kırılmanın gözlemlenmediği görülmektedir. Analizde kullanılan değişkenlerin asimetri grafikleri Şekil 3'de yer almaktadır. 
Şekil 2: Analizde kullanılan değişkenlerin asimetri grafikleri
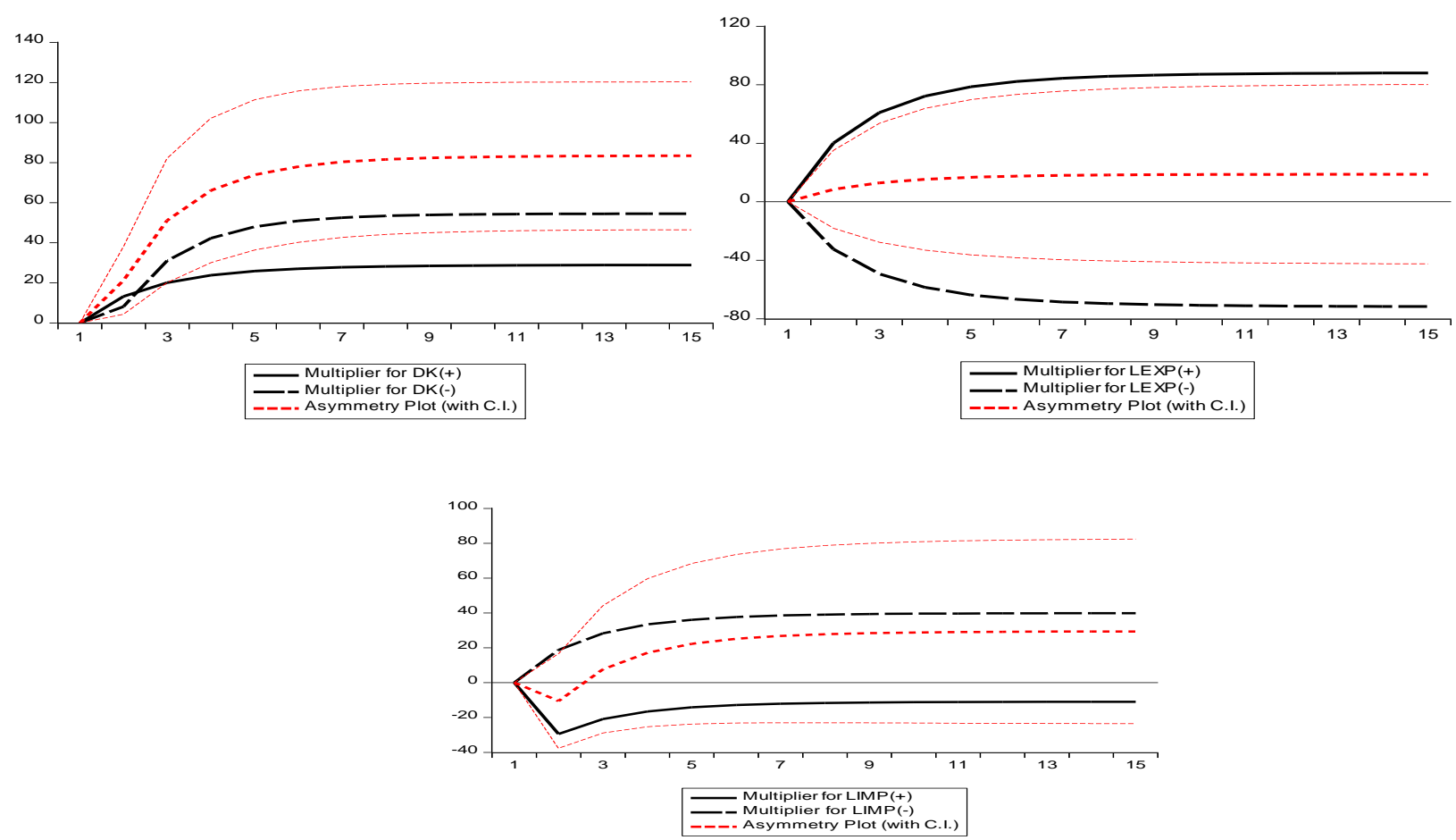

\section{SONUÇ}

Türkiye ekonomisinde 2013Q1-2021Q1 dönemi arasında enflasyon ve döviz kuru arasındaki geçiş etkisinin NARDL yöntemi ile test edildiği bu çalışmada bağımlı değişken ile bağımsız değişkenler arasında kısa ve uzun dönemde asimetri ilişkisinin olduğu gözlemlenmiştir. Buna göre NARDL kısa dönem test sonuçları değerlendirildiğinde döviz kurunda meydana gelen 1 birimlik artış enflasyonda 0.13 birimlik artışa neden olmakta, 1 birimlik azalma ise enflasyonu 0.27 birim azaltmaktadır. İhracatta meydana gelen \%1'lik artış enflasyonu 0.40 birim artırmakta, \%1'lik bir azalma ise 0.31 birimlik azalmaya neden olmaktadır. İthalatta meydana gelen \%1'lik artış ise enflasyonu 0.29 birim artırmakta, \%1'lik azalma ise enflasyonda 0.19 birimlik azalmaya neden olmaktadır. NARDL uzun dönem test sonuçları incelendiğinde ise döviz kurunda meydana gelen 1 birimlik artış enflasyonda 0.28 birimlik artışa neden olmakta, 1 birimlik azalma ise enflasyonu 0.58 birim azaltmaktadır. İhracatta meydana gelen \%1'lik artış enflasyonu 0.86 birim artırmakta, \%1'lik bir azalma ise 0.68 birimlik azalmaya neden olmaktadır. İthalatta meydana gelen \%1'lik artışın etkisi anlamlı sonuç vermemekle birlikte \%1'lik azalma enflasyonda 0.41 birimlik azalmaya neden olmaktadır.

$\mathrm{Bu}$ sonuçlardan hareketle kısa ve uzun dönemde döviz kuru, ihracat ve ithalat miktarlarının enflasyon üzerindeki asimetrik etkileri değerlendirildiğinde, döviz kurunda meydan gelen değişimler fiyat yapışkanlığına neden olmamakla birlikte, kurda meydan gelen azalmaların enflasyonu azaltıcı etkisi artırıcı etkisinden yüksek gerçekleşmektedir. Bu durum döviz kurunun fiyatlar genel seviyesi üzerindeki doğrudan etkisinin yüksek olduğu, döviz kurunun azaltılması durumunda, fiyatlar genel düzeyinin aşağı doğru çekilerek enflasyon probleminin çözümünde etkili olabileceği görüşünü desteklemektedir. Kısa ve uzun dönemde ithalat ve ihracatın fiyatlar genel seviyesi üzerindeki etkilerine bakıldığında ise, ithalat ve ihracatın enflasyonu artırıcı etkilerinin azaltıcı etkilerinden büyük olması nedeniyle, bu değişkenlerin fiyatlar genel düzeyi üzerindeki dolaylı etkilerinin yukarı doğru fiyat yapışkanlıklarına neden olduğunu göstermektedir. Ayrıca ihracat artışının enflasyona neden olması döviz kurunun arttığı dönemlerde yurtiçi piyasaya üretimin kısılmasıyla açıklanabilir. Bu sonuçlar literatürdeki diğer çalışmaların sonuçları ile karşılaştırıldığında döviz kuru ile enflasyon arasındaki ilişkinin olması bakımından diğer 
çalışmalarla örtüşmektedir. Ancak döviz kurunun enflasyon üzerindeki dönemsel etkileri ile doğrudan ve dolaylı etkileri değerlendirildiğinde diğer çalışmalardan farklılaşmaktadır. Buna göre yapılan çalışmalar genellikle uzun dönemde döviz kurunun enflasyon üzerindeki etkisini desteklemekte, kısa dönemde ise döviz kurunun enflasyonu etkilemediği ya da bu etkinin zayıf olduğunu göstermektedir. Ancak bu çalışmada, döviz kurunun enflasyon üzerindeki etkisi hem kısa dönemde hem de uzun dönemde analiz edilerek, döviz kurunun kısa dönemde de enflasyona neden olduğu vurgulanmaktadır. Ayrıca yapılan çalışmalarda döviz kurunun enflasyon üzerindeki etkisinin daha çok ithal malların fiyatları üzerinden dolaylı olarak gerçekleştiği ifade edilmektedir. Bu çalışmada ise, döviz kurunun enflasyon üzerindeki etkisi ithal malları ile ihraç mallarının fiyatlarının yanı sıra, döviz kurundaki değişmeleri de dikkate alarak, doğrudan ve dolaylı olarak test edilmektedir. Dolayısıyla döviz kurunun doğrudan fiyatları etkilemesi ve bu etkinin kısa dönemde anlamlı sonuçlar vermesi, ulusal piyasalarda döviz kurunun doğrudan referans alındığının göstergesi olarak değerlendirilebilir.

$\mathrm{Bu}$ açıklamalara istinaden döviz kurunun fiyatlara geçiş etkisi önemli derecede hissedilmekte ve etkileri bakımından Türkiye' de etkin bir döviz kuru politikasıyla fiyat istikrarı hedefine daha kolay ulaşılabileceği anlaşılmaktadır. Ayrıca döviz kurunun dolaylı olarak ithalat ve ihracat üzerindeki etkileri değerlendirildiğinde ise ortaya çıkan fiyat yapışkanlıkları politika başarısızlığının nedeni olarak gösterilebilir. Dolayısıyla Türkiye'de enflasyonla mücadelede döviz kurunun önemi açıkça gözlemlenmekte, kurun enflasyonist etkisinin ise döviz miktarı artışıyla sağlanabileceği düşünülmektedir. Ülkeye döviz girișinin artırılmasında ihracatın etkisinin yanı sıra fiyat yapışkanlıkları da dikkate alındığında sadece ihracat artışının fiyat istikrarını sağlamada yetersiz kaldığı gözlemlenmektedir. Bu noktada doğrudan yabancı yatırımların miktarının artırılması için politikaların düzenlenmesi ile döviz rezervleri artırılarak döviz kurlarında düşme gerçekleșebilir. 


\section{KAYNAKÇA}

Agénor, P., ve Montiel, P. (2015). Development Macroeconomics: Fourth Edition. Princeton; Oxford: Princeton University Press. doi:10.2307/j.ctvc77j6n.

Altıntaş, H. (2014). Türkiye de Döviz Kurunun Enflasyon Üzerine Geçiş Etkisinin Ekonometrik Analizi 1987 2011. Uludağ Üniversitesi İ.İ.B.F. Dergisi, 33, 163-201.

Bayraktutan, Y., ve Arslan, İ. (2003). Türkiye de Döviz Kuru İthalat ve Enflasyon İlişkisi Ekonometrik Analiz 1980 2000. Afyon Kocatepe Üniversitesi İIBF Dergisi, (2), 89-104.

Carvalho, C., Fernanda N. ve Fang Y. (2019). Monetary Policy and Real Exchange Rate Dynamics in Sticky-Price Models. Federal Reserve Bank of San Francisco. Working Paper 2014-17. http://www.frbsf.org/economicresearch/publications/working-papers/wp2014-17.pdf

Ceylan, F., Tüzün, O., Ekinci, R. ve Kahyaoğlu, H. (2016). Tüketici Kredileri İle Paranın Dolanım Hızı Arasındaki Asimetrik İlişki: Türkiye Üzerine Bir Uygulama. İnsan ve Toplum Bilimleri Araştırmaları Dergisi, 5(7), 2342-2357.

Crucini, Mario J., Shintani, M. ve Tsuruga, T. (2013). Do sticky prices increase real exchange rate volatility at the sector level?. European Economic Review, Elsevier, vol. 62(C), pages 58-72.

Damar, A. O. (2010). Türkiye’ de Döviz Kurundan Fiyatlara Geçiş Etkisinin İncelenmesi. Uzmanlık Yeterlilik Tezi, Türkiye Cumhuriyet Merkez Bankası, Piyasalar Genel Müdürlüğü, Ankara.

Duman, Y. K. (2019). Türkiye de Döviz Kuru ve Enflasyon İlişkisi Ekonometrik Bir Analiz. İktisat ve Toplum, 8(99), 66-84.

Durevall, D. ve Ndung'u, NS. (2001). A dynamic model of inflation of Kenya, 1974-96. Journal of African Economies. Volume 10, Issue 1, pp: 92-125, https://doi.org/10.1093/jae/10.1.92

Dornbusch, R. (1987). Exchange Rates and Prices. The American Economic Review, 77(1), 93-106. Retrieved May 2, 2021, from http://www.jstor.org/stable/1806731.

Ebiringa, 0. T. ve Anyaogu, N. B. (2014). Exchange rate, inflation and interest rates relationships: An autoregressive distributed lag analysis, Journal of Economics and Development Studies, 2(2): 263-279.

Ekinci, R., Tüzün, O., ve Kahyaoğlu, H. (2015). Dış Ticaret Hadleri Ekonomik Büyüme İlişkisi: Türkiye Üzerine Bir Uygulama. Optimum Ekonomi ve Yönetim Bilimleri Dergisi, 2(2), 83-100.

Fetai, B. , Koku, P. S. , Caushi, A. ve Fetai, A. (2016). The Relationship Between Exchange Rate And Inflation: The Case of Western Balkans Countries. Journal of Business Economics and Finance, 5 (4), 360-364. DOI: 10.17261/Pressacademia.2017.358

Gül, E, ve Ekinci, A. (2015). Türkiye'de Reel Döviz Kuru ile İhracat ve İthalat Arasındaki Nedensellik İlişkisi: 1990-2006. Dumlupınar Üniversitesi Sosyal Bilimler Dergisi, (16), Retrieved from https://dergipark.org.tr/tr/pub/dpusbe/issue/4758/65361

Granger, C.W.J., Yoon, G., (2002). Hidden cointegration. Working Paper, University of California, San Diego.

Kara, A. ve Nelson, E. (2002). The Exchange Rate and Inflation in the UK. Discussion Papers 11, Monetary Policy Committee Unit, Bank of England.

Monfared, S. S ve Akın, F. (2017). "The Relationship Between Exchage Rates and Inflation the Case Of Iran". European Journal of Sustainable Development, 6(4), 329-340. Doi: 10.14207/ejsd.2017.v6n4p329. 
Moroşan, G. ve Zubaş I. M. (2015). Interest Rate, Exchange Rate and Inflation in Romania, Correlates and Interconnection. Journal of Public Administration, Finance and Law, 8: 146-160.

Nchor, D. ve Darkwah, S. A. (2015). Inflation, Exchange Rates and Interest Rates in Ghana: an Autoregressive Distributed Lag Model. Acta Universitatis Agriculturae et Silviculturae Mendelianae Brunensis 63(3):969-977. DOI: 10.11118/actaun201563030969.

Osabuohien, E., Obiekwe E., Urhie E. ve Osabohien R. (2018). Inflation rate, exchange rate volatility and exchange rate pass-through nexus the Nigerian experience. Journal of Applied Economic Sciences 13(2):574-585.

Öner, H. (2018). Döviz Kuru ve Enflasyon Arasındaki Nedensellik İlişkisi Türkiye Uygulaması. Hitit Üniversitesi Sosyal Bilimler Enstitüsü Dergisi, 11(1), 359-374.

Özcan, B. (2014). Gelişmekte Olan Ekonomilerde Enflasyonun Belirleyenleri Dinamik Panel Veri Analizi. Cumhuriyet İIBF Dergisi, 15(1), 33-52.

Pesaran, M.H., Shin, Y., Smith, R.J., (2001). Bounds testing approaches to the analysis of level relationships. Journal of Applied Econometrics, 16, 289-326.

Sheefeni, J. ve Ocran, M. (2014). Exchange Rate Pass-Through to Domestic Prices in NAMIBIA: Svar Evidence. Journal of Economic and Financial Sciences, 7(1), 89-102.

Shin, Y., Yu, B., Greenwood-Nimmo, M., (2014). Modelling asymmetric cointegration and dynamic multipliers in an ARDL framework. In: Horrace, W.C., Sickles, R.C. (Eds.), Festschrift in Honor of Peter Schmidt. Springer Science \& Business Media, New York (NY).

Svensson, Lars E. O. (2000). Open-economy inflation targeting. Journal of International Economics, vol. 50(1), pages 155-183.

Uçan, O. ve Aytekin, İ. (2017). Döviz Kuru Enflasyon İlişkisi Türkiye Örneği 2004-2017. Presented at the International Conference on Multidisciplinary, Science, Engineering and Technology (IMESET'17 Bitlis).

Utkulu, U., ve Ekinci, R. (2016). Uluslararası Petrol ve Gıda Fiyatlarından İç Fiyatlara Asimetrik ve Doğrusal Olmayan Fiyat Geçişkenliği Türkiye İçin NARDL Modeli Bulguları. Finans Politik Ekonomik Yorumlar, 53(617), 9-22.

Woo, Wing T. (1984). Exchange Rates and the Prices of Nonfood, Nonfuel Products. Brookings Papers on Economic Activity, Economic Studies Program, The Brookings Institution, vol. 15(2), pages 511-536. 


\section{EXTENDED ABSTRACT}

\section{The Inflation Effect of Exchange Rate and Price Stickiness in Turkey: NARDL Approach}

\section{Introduction}

With the effect of globalization, the disappearance of borders between countries accelerates international goods exchanges and increases the need for foreign exchange required for international exchanges. This situation increases the impact of changes in exchange rates on the economy. Fluctuations in foreign exchange rates cause an inflationary process by raising domestic prices with an increase in costs in industries that produce or sell based on imports. Therefore, in this study, the asymmetric relationship between inflation and exchange rate, export and import between 2013Q12021Q1 in Turkey is tested with the NARDL method. As a result of the study, it has been observed that foreign exchange, import and export have an asymmetric effect on inflation and this process causes price stickiness in Turkey.

\section{Data Set and Method}

In the study, the pass-through effect between inflation and exchange rate in the Turkish economy between the period of 2013Q1-2021Q1 is tested with the NARDL method. The data used in the analysis were obtained from the CBRT EDDS database. In terms of simplification, the variables used in the study are INF: Inflation, DK: Exchange rate, EXP: Exports and IMP: imports.

\section{Empirical Findings}

In this study, in which the pass-through effect between inflation and exchange rate in the Turkish economy between 2013Q1-2021Q1 was tested with the NARDL method, it was observed that there was an asymmetry relationship between the dependent variable and the independent variables in the short and long term. Accordingly, when the NARDL short-term test results are evaluated, a 1-unit increase in the exchange rate causes an increase of 0.13 units in inflation, while a 1-unit decrease reduces inflation by 0.27 units. A $1 \%$ increase in exports increases inflation by 0.40 units, while a $1 \%$ decrease causes a 0.31 unit decrease. A $1 \%$ increase in imports increases inflation by 0.29 units, while a $1 \%$ decrease causes a 0.19 unit decrease in inflation. When NARDL long-term test results are analyzed, a 1-unit increase in the exchange rate causes an increase of 0.28 units in inflation, while a 1-unit decrease reduces inflation by 0.58 units. A $1 \%$ increase in exports increases inflation by 0.86 units, while a $1 \%$ decrease causes a 0.68 unit decrease. Although the effect of a $1 \%$ increase in imports does not yield significant results, a $1 \%$ decrease causes a 0.41 unit decrease in inflation.

\section{Discussion and Conclusion}

When the asymmetric effects of exchange rates, exports and imports on inflation are evaluated in the short and long term, the changes in the exchange rate do not cause price stickiness, but the inflationreducing effect of the decrease in the exchange rate is higher than the increasing effect. This situation supports the view that the direct effect of the exchange rate on the general level of prices is high, and that in case of a decrease in the exchange rate, the general level of prices can be pulled down, which can be effective in solving the inflation problem. When the effects of imports and exports on the general price level in the short and long term are analyzed, it is seen that the indirect effects of these variables on the general price level cause upward price stickiness, since the inflation-increasing effects of imports and exports are greater than their reducing effects. In addition, the increase in exports causing inflation can be explained by the reduction in production in the domestic market during periods of increased exchange rate. When these results are compared with the results of other studies in the literature, they overlap with other studies in terms of the relationship between exchange rate and inflation. However, when the periodic effects of the exchange rate on inflation and 
its direct and indirect effects are evaluated, it differs from other studies. Accordingly, studies generally support the effect of exchange rate on inflation in the long run, and show that the exchange rate does not affect inflation in the short run or this effect is weak. However, in this study, the effect of exchange rate on inflation is analyzed both in the short term and in the long term, and it is emphasized that the exchange rate causes inflation in the short term. In addition, studies show that the effect of exchange rate on inflation occurs indirectly through the prices of imported goods. In this study, however, the effect of the exchange rate on inflation is tested directly and indirectly, taking into account the changes in the exchange rate as well as the prices of imported and exported goods. Therefore, the fact that the exchange rate directly affects the prices and this effect gives meaningful results in the short term can be considered as an indicator that the exchange rate is taken as a direct reference in the national markets. 